
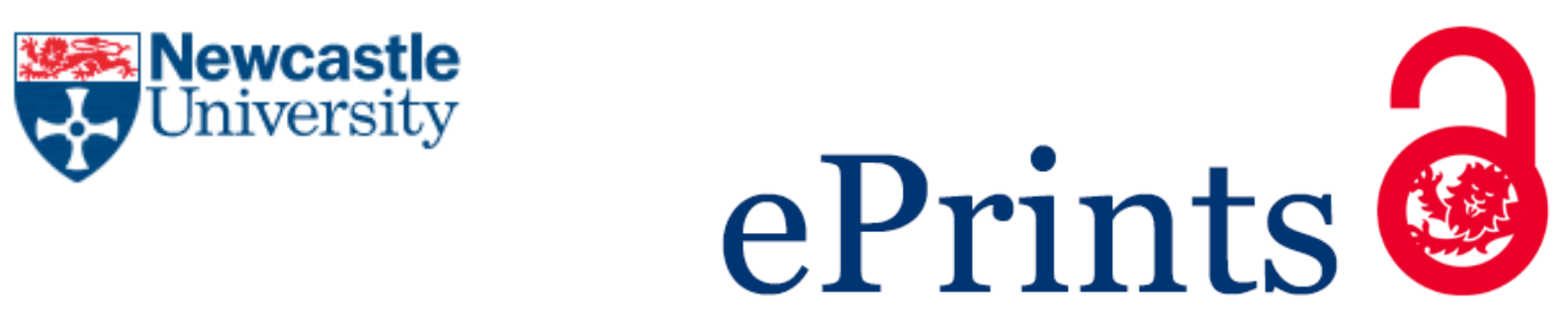

Sciberras EA, Zahawi B, Atkinson DJ.

Reducing shipboard emissions - Assessment of the role of electrical

technologies.

Transportation Research Part D: Transport and Environment 2017, 51, 227 239.

\title{
Copyright:
}

(C) 2017. This manuscript version is made available under the CC-BY-NC-ND 4.0 license

DOI link to article:

http://doi.org/10.1016/j.trd.2016.10.026

Date deposited:

$21 / 04 / 2017$

Embargo release date:

28 July 2018

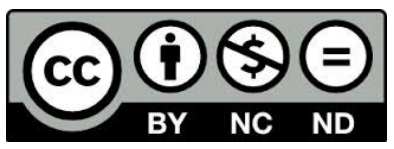

This work is licensed under a

Creative Commons Attribution-NonCommercial-NoDerivatives 4.0 International licence 


\section{Reducing shipboard emissions - assessment of the role of electrical technologies}

Edward A Sciberras ${ }^{\mathrm{a}, \mathrm{b} *}$, Bashar Zahawi ${ }^{\mathrm{b}}$, David J Atkinson ${ }^{\mathrm{a}}$

a School of Electrical and Electronic Engineering, Newcastle University, UK

${ }^{\mathrm{b}}$ Department of Electrical and Computer Engineering, Khalifa University, Abu Dhabi, UAE

* Corresponding author: School of Electrical and Electronic Engineering, Merz Court, Newcastle University, Newcastle upon Tyne, NE1 7RU, UK. Email: edward.sciberras@ncl.ac.uk Tel: $+44(0) 1912087208$

\section{Abstract}

Saving fuel and reducing emissions are major drivers in the marine industry, with a large number of potential modifications and machinery options available to enable the greening of shipping. Assessing which technology and what combination of solutions gives favourable economic results needs careful consideration of the vessel's operational profile. Electrification of shipboard systems introduces operational flexibility, offering the potential for fuel savings and emission reductions. Auxiliary drives, energy storage and onshore power supply are three approaches which address the issues of ship fuel consumption/emissions, specifically during in-harbour operation of vessels. In this paper, the impact of these three technologies on ship environmental performance and energy consumption is assessed by considering a real case RoRo vessel sailing a real operational profile. Models of the resultant system are built such that the machinery configurations can be analysed separately or in conjunction with each other. The results stress the importance of the operational profile of the vessel, showing significant fuel and emissions reductions during in-harbour operations but relatively small savings when considering operation through a complete return voyage. The sensitivity of the results to fuel and utility costs are also considered and shown to have a large impact on the economic feasibility (or otherwise) of different solutions.

\section{Keywords}

Auxiliary drives, energy storage, batteries, cold ironing, onshore power supply, marine hybrid vessel.

\section{Nomenclature}

CPP

ECA

HFO

LUT

MGO

OPS

RoRo
Controllable Pitch Propeller

Emission Control Area

Heavy Fuel Oil

Look Up Table

Marine Gasoil

Onshore Power Supply

Roll-On Roll-Off 


\section{Introduction to paper}

Environmental concerns play a major role in decision-making processes in all industries. In the marine industry, legislative efforts aim to provide incentives to influence such decisions and reduce the environmental impact of shipping activities. Examples of this include the IMO's ECA Sulphur limits (IMO, 2005), and the European Union's Sulphur directive (The European Parliament and the Council of the European Union, 2012) which both address the Sulphur content of fuel. Compliance with environmental legislation also has monetary benefits in terms of the avoidance of fines and potential savings on fuel costs. The application of these environmentally-friendly solutions however is not a silver bullet, as the result is highly dependent on the actual operational profile of the vessel and its onboard machinery systems. Hence any potential application of a new technology must be comprehensively assessed according to the expected usage and applied in circumstances that fully exploit the benefits of such solutions.

Most vessels nowadays use diesel engines for propulsion as well as auxiliary power generation (Argyros et al., 2014). These typically run on Heavy Fuel Oil (HFO) for economic reasons. This fuel, however, is not the cleanest in terms of emissions and diesel engines are not at their ideal operating point when working at off-design conditions, such as when manoeuvring at slow speeds. What's more, slow sailing typically takes place during harbour approach, which is close to shore and consequently, human habitation. This in-harbour period has a higher direct impact on human health than the period spent sailing at sea, despite the duration being typically much shorter for an ocean sailing vessel (Banks et al., 2013). The exact proportion of times spent in each condition is of course highly dependent on individual vessels and their operation. Once berthed, in-harbour emissions do not cease, but ships typically provide their auxiliary load while in-harbour by running their auxiliary generators.

Electrification of shipboard systems provides extra flexibility, and offers the potential to help reduce fuel consumption and emissions. Electrified systems facilitate the integration of multiple sources of power and the use of energy storage, decoupling prime mover operation and power demand. This can ameliorate diesel engine operating points, since engine loadings can potentially be improved. Added flexibility is introduced by hybridisation of the powertrain, allowing power to be provided to the propulsion system via alternative means through the electrical system. Additional powering options are available when berthed in the form of onshore power supply.

In this paper, an assessment of the suitability and potential impact of the various electric solutions is performed, based on a real vessel and its operating profile including the in-harbour and harbour approach periods, using available data from the vessel's operation as the basis for quantifying emissions and fuel consumption levels. Firstly, hybridisation of the propulsion system is considered, with the fitting of a bidirectional auxiliary drive permitting electric propulsion at slow ship speeds. This is further expanded upon by the application of onboard batteries, permitting stored energy to be used to provide propulsion via the auxiliary drive. Finally, onshore power supply is considered, which enables the vessel to connect to the shoreside grid when berthed, such that the onboard generators can be turned off. This provides the onboard electrical load as well as charging of the batteries.

The benefits of auxiliary drives and shore supply have been studied previously as separate, single options. In (Sciberras et al., 2015b), an auxiliary drive was considered, powered by the onboard 
generators during manoeuvring, where different machine choices and topologies were examined and discussed. Similarly, in (Sciberras et al., 2015a) onshore power supply was studied for the berthed period, together with the impact on the shoreside electrical network.

In this paper, the complete operational profile for a case vessel is considered, and the performance of the auxiliary drive, shore supply and battery storage systems are assessed in terms of fuel consumption and emission savings. This is based on a real operating profile, sailed by a $138.5 \mathrm{~m}$ RoRo vessel between France and Spain along the Motorway of the Sea of Western Europe. The case vessel is a typical RoRo ship with a single shaft installation with a medium-speed engine driving a fixed speed Controllable Pitch Propeller (CPP) via a main reduction gearbox with the main particulars described in Table I. The ship sails the regular return voyage of around $1,850 \mathrm{~km}$ with a journey time of $60 \mathrm{hrs}$. The operation can be divided into three segments, namely at sea, manoeuvring and at berth. While at sea, the ship sails at a constant speed, before slowing down and sailing at a lower constant speed until berth is approached. These two conditions are illustrated in Figure 1 and Figure 2 respectively, based on actual onboard measurements. The proportion of time spent in each condition is summarised in Table II, clearly showing how the at sea period constitutes the majority of the voyage's duration. The main engine runs on Heavy Fuel Oil (HFO), while the auxiliary onboard generators run on Marine Gas Oil (MGO).

Table I Case vessel main particulars

$\begin{array}{ll}\text { Deadweight } & 7,629 \mathrm{t} \\ \text { Service speed } & 20.2 \mathrm{kn} \\ \text { Propulsion system } & 1 \times \mathrm{CPP} \text { at } 150 \mathrm{rpm} \\ \text { Main engine } & 1 \times 14,480 \mathrm{~kW} \text { at } 500 \mathrm{rpm} \\ \text { Auxiliary generators } & 2 \times 1,421 \mathrm{~kW}\end{array}$

Table II. Overview of operating conditions durations over a single leg of the journey.

\begin{tabular}{lll} 
Condition & Percentage Duration & Time (Hrs) \\
\hline At sea & $75 \%$ & 21 \\
\hline Manoeuvring & $5 \%$ & 1.4 \\
\hline Berthed & $20 \%$ & 5.6 \\
\hline
\end{tabular}




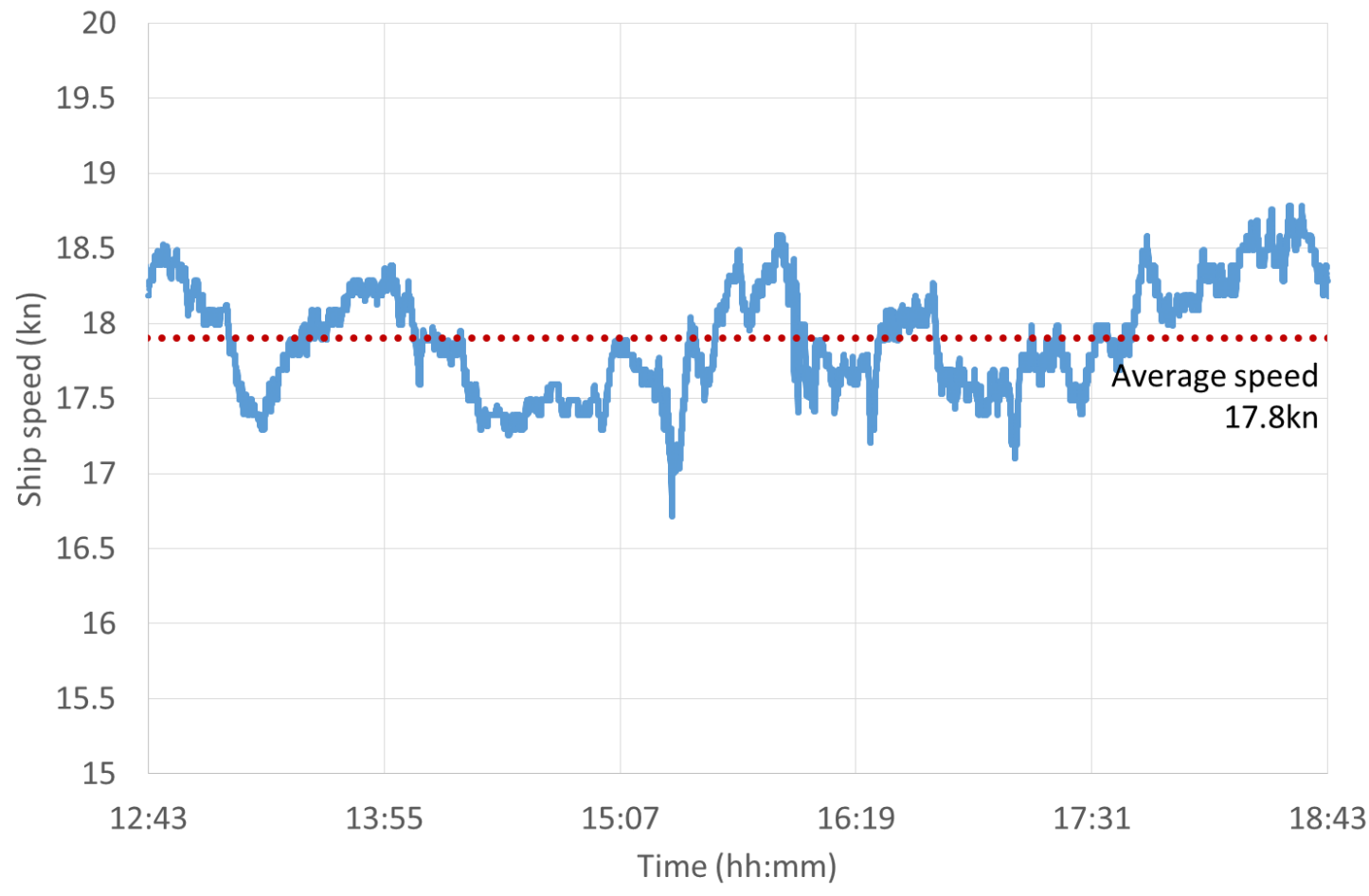

Figure 1. Snapshot of ship speed while free sailing at sea.

—Main engine power —Ship speed

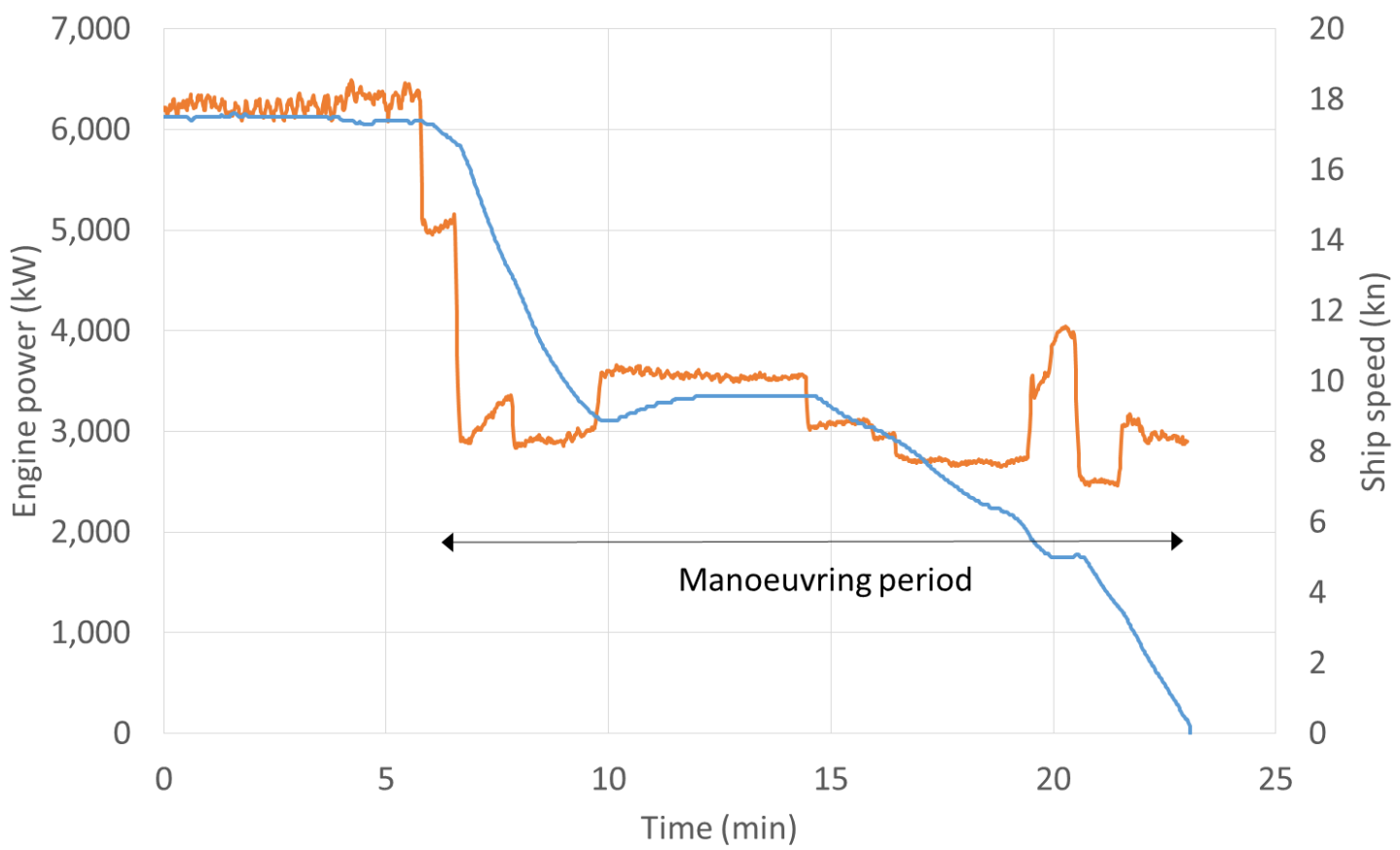

Figure 2. Manoeuvring period detail showing vessel power and speed profiles.

In this work, models of the case vessel with auxiliary drives, battery storage and onshore power supply were built, and run with the ship's operating profile as input. Different combinations of these technologies were analysed in order to examine the effects on fuel consumption and emissions. Combinations which relied mostly on the main engine for power by eliminating shore supply realised the highest fuel savings, especially when using the main engine to charge the onboard battery 
storage. However the largest emission savings were seen when minimising the main engine's usage by maximising usage of any onshore power supply. The results also highlight the sensitivity to fuel and energy prices. Fuel and shore supply operating costs are extremely variable, and this work demonstrates the effect of pricing on the economic viability of various solutions.

The remainder of this paper is organised as follows: Sections 2, 3 and 4 describe the auxiliary drives, onboard battery storage and onshore power supply technologies, respectively, and how they can be applied to the case vessel described. The proposed machinery systems are then modelled in Section 5 such that the resultant fuel consumption and airborne emissions can be estimated when simulated over the entire voyage profile as well as when considering the in-harbour period only. Different configurations were examined and the resultant savings (or otherwise) obtained and evaluated. The conclusions drawn from the study are then discussed and presented in Section 6 .

\section{Hybridised powertrains}

A conventional propulsion system generally consists of a propeller driven by a diesel engine.

Depending on the engine speed, this can either take the form of a direct drive, or include a stepdown gearbox between main engine and propeller. The term 'auxiliary drive' refers to an electrical machine mounted on the propulsion shaft, together with a bidirectional power electronic converter. This permits the propeller to be powered from the onboard electrical network, giving an alternative power source to the main engine. Additionally, the bidirectional nature of the auxiliary drive permits power to be fed back into the electrical network (Alexander, 2015; Castles et al., 2009). This allows the onboard electrical load to be supplied from the main engine, which is more economical than running the auxiliary generators since this runs on cheaper HFO. Conventional shaft generators consist of synchronous alternators coupled to the propulsion shaft, able to generate power when the shaft speed is constant at the design speed (Prousalidis et al., 2005). Shaft generators are therefore most appropriate for Controllable Pitch Propeller (CPP) installations where a constant shaft speed is maintained.

The addition of a power electronic converter permits variable speed operation of the electrical machine by modulating the voltage and current waveforms. A converter with an Active Front End permits power flow in both directions (into and out of the drive) such that the operating region of the electrical machine is now broadened to allow four quadrant operation, i.e. motoring/generation in the forward/reverse direction. However, this flexibility comes at significant additional expense compared to a unidirectional drive, doubling the power electronic component count (Sciberras et al., 2015b). To take advantage of variable speed operation, the possibility of combinatory mode operation i.e. varying of both propeller pitch and speed can now permit the efficiency point of the propeller to be optimally adjusted (Murphy et al., 2012).

The choice of electrical machine for auxiliary drive application is highly dependent on cost. Induction machines are the most popular type of electrical machine in industrial traction and marine applications, being simple, rugged and of cheap construction. Permanent magnet machines have nominally higher efficiency and power density, but come at higher initial cost due to the use of rare earth magnetic materials (Finch and Giaouris, 2008). The speed rating of the machine also affects cost as well as size. Slow-speed machines can be mounted directly on the propeller shaft, eliminating the need for any mechanical gearboxes thus reducing losses. However slower-speed machines are bulkier and more expensive than their higher-speed equivalents. In this work, an $875 \mathrm{~kW}$ permanent magnet machine was chosen, mounted on the high-speed side of the reduction gearbox, due to compactness and size considerations being an important concern for this installation. Table III lists the main parameters describing a commercially-available permanent magnet machine, selected for 
this application. Figure 3 shows the setup of an auxiliary drive, mounted on the high-speed side of the main reduction gearbox. A bidirectional power electronic converter is included, connected to the onboard electrical grid.

Table III Electrical machine main parameters.

$\begin{array}{ll}\text { Rated power } & 875 \mathrm{~kW} \\ \text { Rated speed } & 400 \mathrm{rpm} \\ \text { Efficiency at rated } & 96.5 \% \\ \text { Mass } & 4,680 \mathrm{~kg} \\ \text { Rated voltage } & 690 \mathrm{~V}\end{array}$

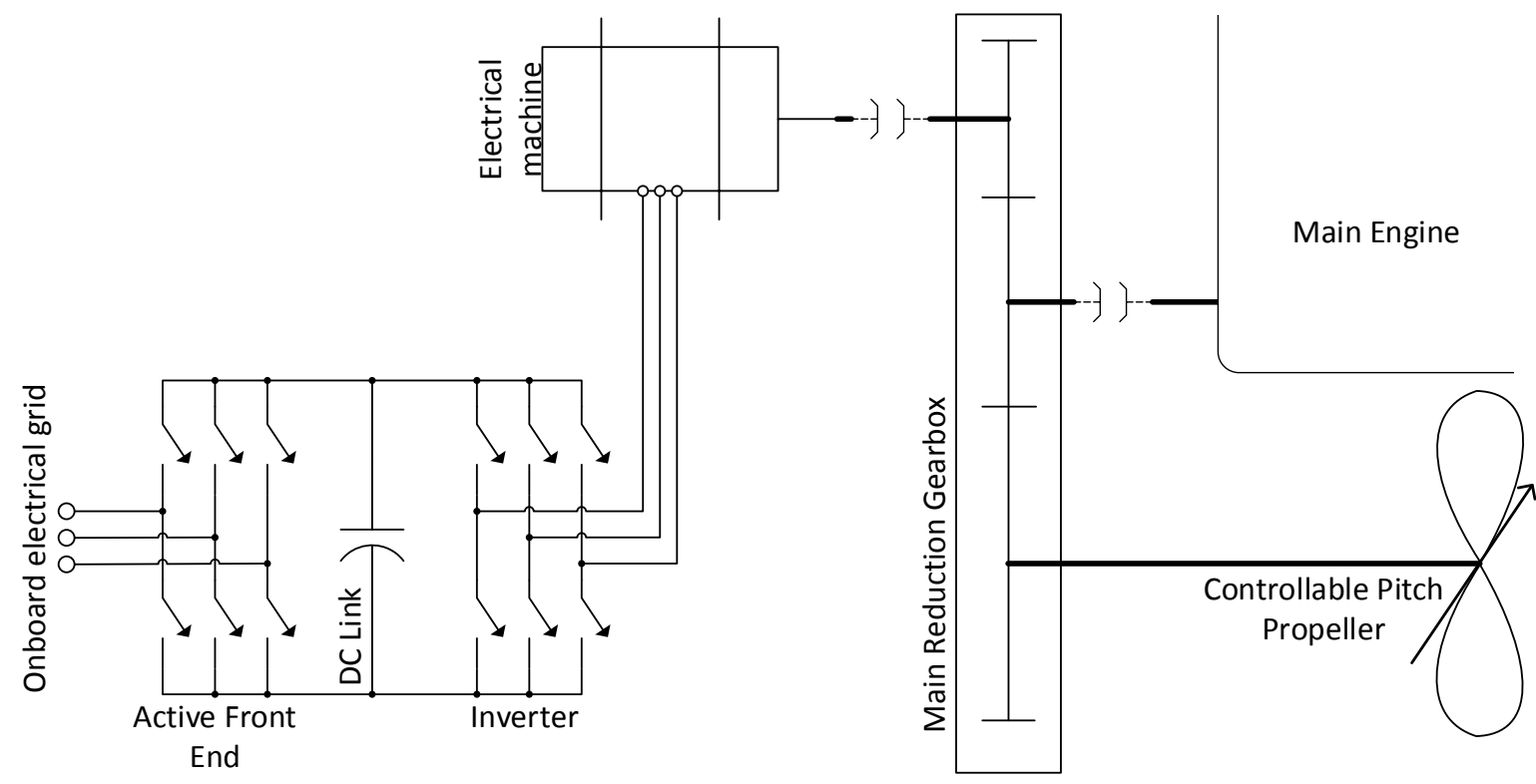

Figure 3. Schematic of auxiliary drive setup.

\section{Onboard storage}

In a conventional system without any storage capacity, generated and consumed powers must balance at all instants in time without any buffering. Storage permits decoupling of supply and demand, giving the possibility of prime mover operation at times not dictated by propulsion demand. Conversely, the future use of this stored energy at a more beneficial time (from an emissions/economy point of view) enables the advantages of a cleaner, less polluting source to be exploited at a time when the source would not be otherwise available.

Various energy storage solutions are available for transport applications, with the most prominent being fuel cells, batteries, supercapacitors and flywheel energy storage. Fuel cells have been seeing increased popularity, and directly convert Hydrogen fuel to electrical energy. However they are relatively fragile, and do not cope well with changes in loads. Supercapacitors are excellent for fast charging or discharging and have a very high power density, but are not ideal for storing significant amounts of energy (Alahakoon and Leksell, 2015).

Batteries are a well-established storage solution, and widely used in transport applications. Several battery types are available, with individual attributes making them suited for particular demands. Among these, Lithium-ion family derivatives are among the most popular, exhibiting power and 
energy densities on a scale useful for shipboard application, robustness as well as repeated cycling capacity (Horiba, 2014; Vazquez et al., 2010).

Lithium batteries are commercially available in marine certified packages consisting of a number of stacked battery modules to obtain the required energy capacity, as well as the associated power electronic converters together with the battery management system. For large capacity applications, containerised solutions are readily available for onboard installation with up to $1 \mathrm{MWh}$ capacities available in standardised 20 -foot containers.

Battery selection must be matched to expected usage, satisfying capacity requirements (energy) as well as current demands (power capability). Depth of discharge affects battery life, hence for prolonged lifetime, sufficient excess battery capacity is factored in at the design stage to account for future battery degradation. Similarly, the battery charging rate also affects the battery lifetime, with slower charging rates prolonging battery life. For this work, a battery was sized in order to provide propulsion and auxiliary power during the longest manoeuvring periods with a $60 \%$ depth of discharge. This works out at a battery capacity of $3,000 \mathrm{kWh}$. This is a significant battery size, which would obviously entail significant cost. In terms of physical size, this can be easily fitted into three 20-foot off the shelf containers. Of course this would come at a cost of decreased cargo space, or a $2 \%$ reduction in the lane-metre capacity of the vessel. The batteries are charged at a rate of $500 \mathrm{~kW}$, which is sufficient to fully recharge the batteries from the shore supply in the berthed time. This assumes that sufficient power capacity is available from shore.

\section{Onshore power supply}

Once a ship is berthed, power requirements are considerably lower than the propulsion demands when at sea. However emissions when berthed, occur close to human habitation, thus the total cost of these emissions has a more direct impact on health (McArthur and Osland, 2013). Onshore Power Supply (OPS), also known as cold ironing refers to the connection of a berthed vessel to an electric supply from shore. This permits onboard generators to be shut down, thus reducing or eliminating airborne emissions while the vessel is in port. The shore supply should therefore be able to supply the total onboard electrical demand during the in-harbour period (Hall, 2010). This would include the auxiliary electrical load, as well as demand from any battery charging systems.

The connection requirements for the connection of a single vessel to the shore supply are shown in Figure 4, outlining the fundamental components as described in ("IEC/ISO/IEEE Utility Connections in Port-Part 1," 2012). This standard aims to harmonise the requirements for providing shore supplies, such that vessels can expect compatible connections delivering power of the appropriate quality at any compliant port (Khersonsky et al., 2007). This refers to matching voltage and frequency of the supply, as well as a connection whose power quality in terms of harmonic distortion does not adversely affect the vessel or any other consumers on the network (Sciberras et al., 2015a). 


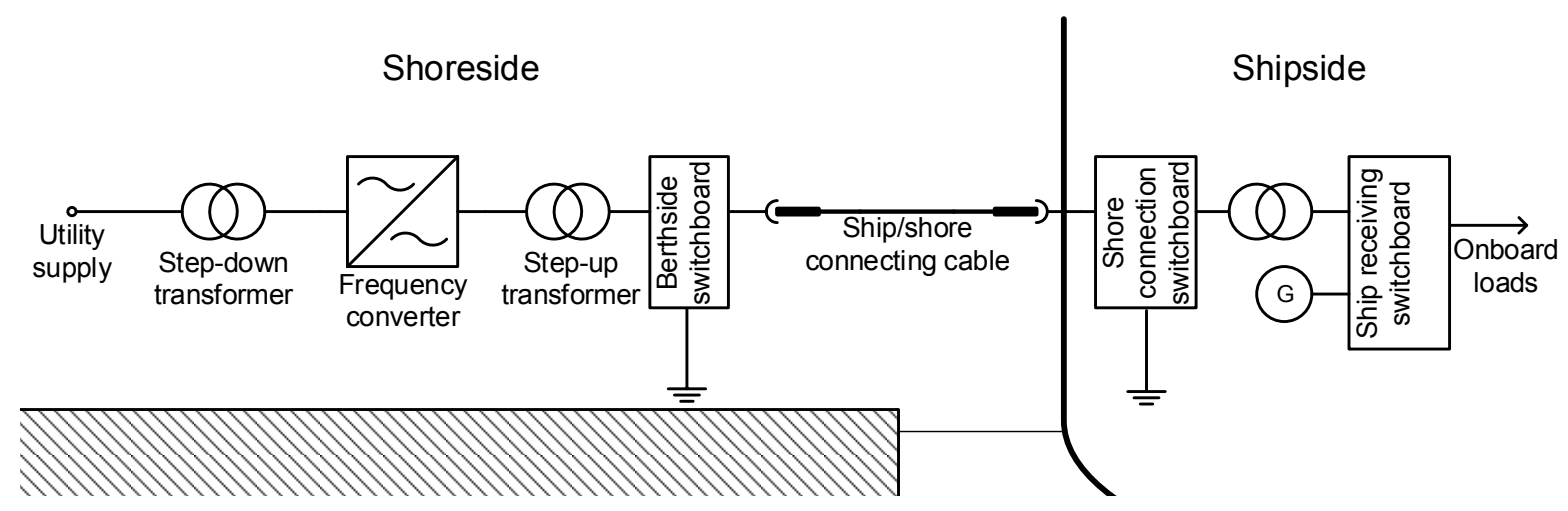

Figure 4. Shore connection layout for a single supply ("IEC/ISO/IEEE Utility Connections in Port-Part 1," 2012).

Among the salient points emerging from ("IEC/ISO/IEEE Utility Connections in Port-Part 1," 2012), is that the electrical frequency supplied to a berthed vessel must match the frequency demanded by the ship. This implies that frequency conversion must be performed on shore, raising the cost of shoreside infrastructure, as the frequency converters are a significant expense in shore-supply installations. Also required on shore are isolation transformers which provide galvanic isolation between connected vessels as well as between vessel and shore.

An onboard transformer is also necessary if the ship's voltage level and the supplied voltage do not match. This ensures that vessels with a non-standard onboard supply can still connect, with the expectation that voltage matching is performed onboard. Another essential feature of the onboard system is the shore-receiving switchboard which must ensure that synchronisation and interlocking of supplies occur for seamless transition of power.

The main motivation behind onshore power supply is environmental, with the elimination or reduction of in-harbour emissions being the main concern. With power being supplied externally to the vessel, the onboard generators which typically run on diesel fuel can be shut down. The actual overall emissions will be dependent on the actual source of power which is described by the generation mix of the location of connection. Countries with a high proportion of fossil-fuelled generation will have correspondingly higher emissions, with a dependence on coal leading to even higher $\mathrm{CO}_{2}$ emission rates (Hall, 2010). Renewables and nuclear generation are considered as producing no airborne emissions during operation and thus serve to reduce the emissions generated when ships are in-harbour in locations with such supplied. The approach taken in this work was to derive individual fuel-dependent emission factors and then scale these according to the generation mix employed. This allows a country's average emission factor to be estimated, reflecting national energy policies.

In this study, the ship sails a fixed route between France and Spain, each with the generation mix described in Table $I V$ and the corresponding emission factors given in

Error! Reference source not found. These emission factors relate the mass of airborne emissions to the energy at the consumer end, accounting for the averaged transmission loss in the network. Immediately apparent from the tables is the lower emission figures for countries with a high nuclear contribution. The generation mix also influences the cost of electricity to the consumer, with fossil fuel dependent mixes being highly variable and dependent on world oil prices. Energy costs are highly variable, and can change significantly in a way that is impossible to predict. In this work costs are presented based on figures available from the European Statistics Office (Eurostat), with the appreciation that these can change drastically, influencing the balance of results. Similarly, the costs are also highly dependent on commercial aspects, such as the negotiation of contracts as well as the 
actual costs charged to the berthed vessels by the port operators. Thus the absolute value of the cost figures is highly subjective.

Table IV Generation mix (IEA, 2012).

\begin{tabular}{llllll} 
Country & Coal & Oil & Gas & Nuclear & Renewables \\
\hline Spain & $12.7 \%$ & $6.5 \%$ & $37 \%$ & $18 \%$ & $24 \%$ \\
\hline France & $5 \%$ & $1 \%$ & $4 \%$ & $76 \%$ & $13 \%$ \\
\hline
\end{tabular}

Table V Emission factors and cost for electricity consumed (Sciberras et al., 2016).

\begin{tabular}{|c|c|c|c|c|}
\hline Country & $\mathrm{CO}_{2}(\mathrm{~g} / \mathrm{kWh})$ & $\begin{array}{l}N O_{x} \\
(g / k W h)\end{array}$ & $\mathrm{SO}_{2}(\mathrm{~g} / \mathrm{kWh})$ & Cost (USD/kWh) \\
\hline Spain & 331.10 & 0.52 & 0.36 & 0.08 \\
\hline France & 75.64 & 0.14 & 0.11 & 0.048 \\
\hline
\end{tabular}

\section{Quantification of emissions and fuel consumption}

The complete setup of all the components described in this work is shown in Figure 5 . The OPS incoming connection and the battery storage system are shown connected to the ship's low voltage busbar, and will be described in the following sections. The arrows in the figure illustrate the direction of power flows, highlighting the increased flexibility associated with electrification. This emphasises the increased combinations of possible machinery configurations to supply power in order to meet the ship's mission.

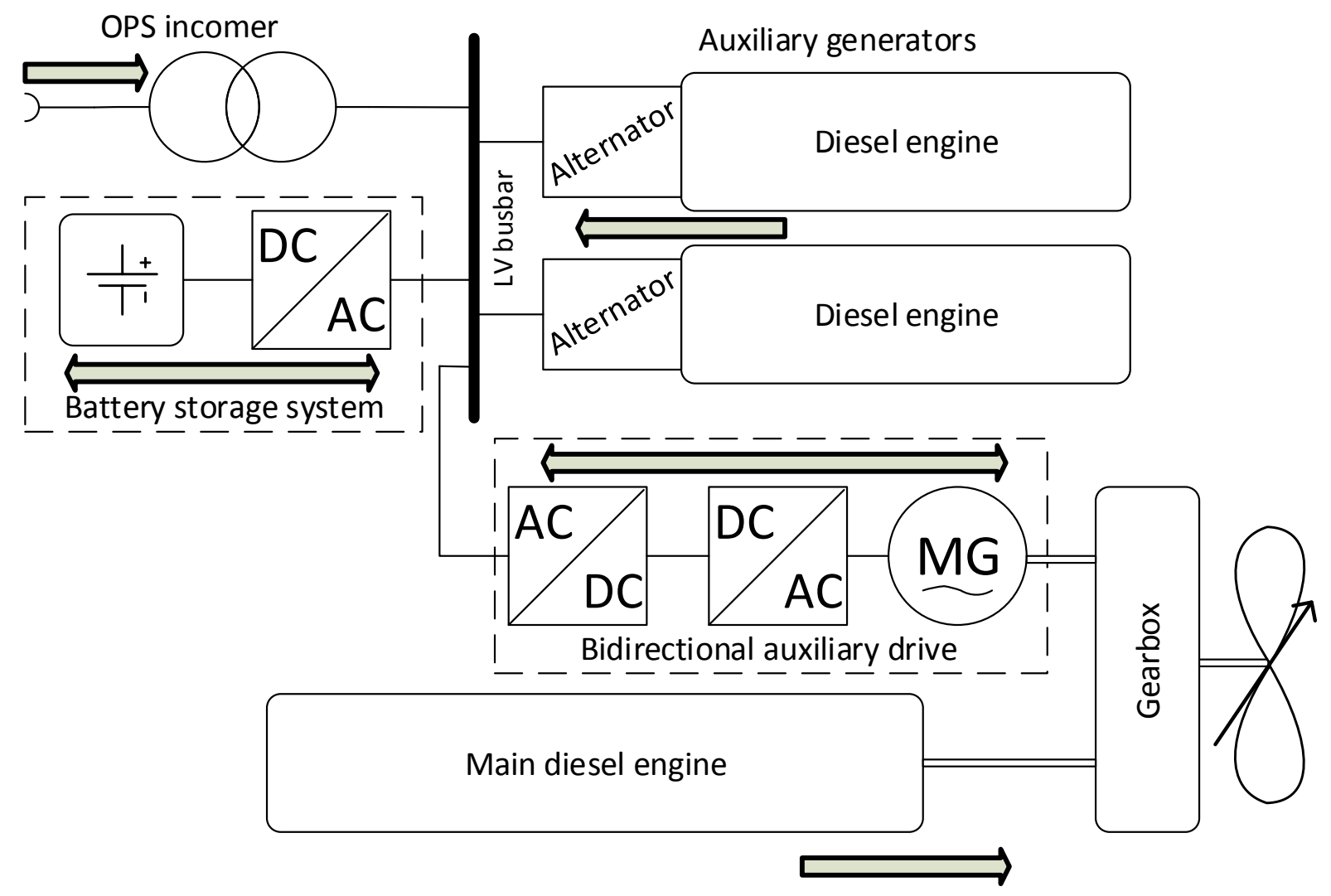


Figure 6 shows the approach adopted in modelling the complete ship system of Figure 5 . The model takes as inputs the ship speed and auxiliary power demand, and returns the fuel consumption and emissions for the simulated voyage over the complete profile. The individual models use efficiency Look Up Tables (LUTs) which have been generated using detailed component models at the operating points of interest. This permits the losses at each stage to be estimated, based on the machinery configuration selected, returning the fuel used to supply the required energy. The electric drive efficiency LUT was built using a detailed $\mathrm{d}$-q model of an electrical machine and converter, run at the operating points of relevance to extract the steady-state efficiency values (Sciberras et al., 2015b). The battery is modelled as an accumulator, since we are mainly interested in the energy balance over the simulated profile. Propulsion demands are obtained from the ship's operating profile in conjunction with trials data in order to obtain the vessel's speed-power characteristic. The gearbox (and transmission system) is modelled as a constant loss.

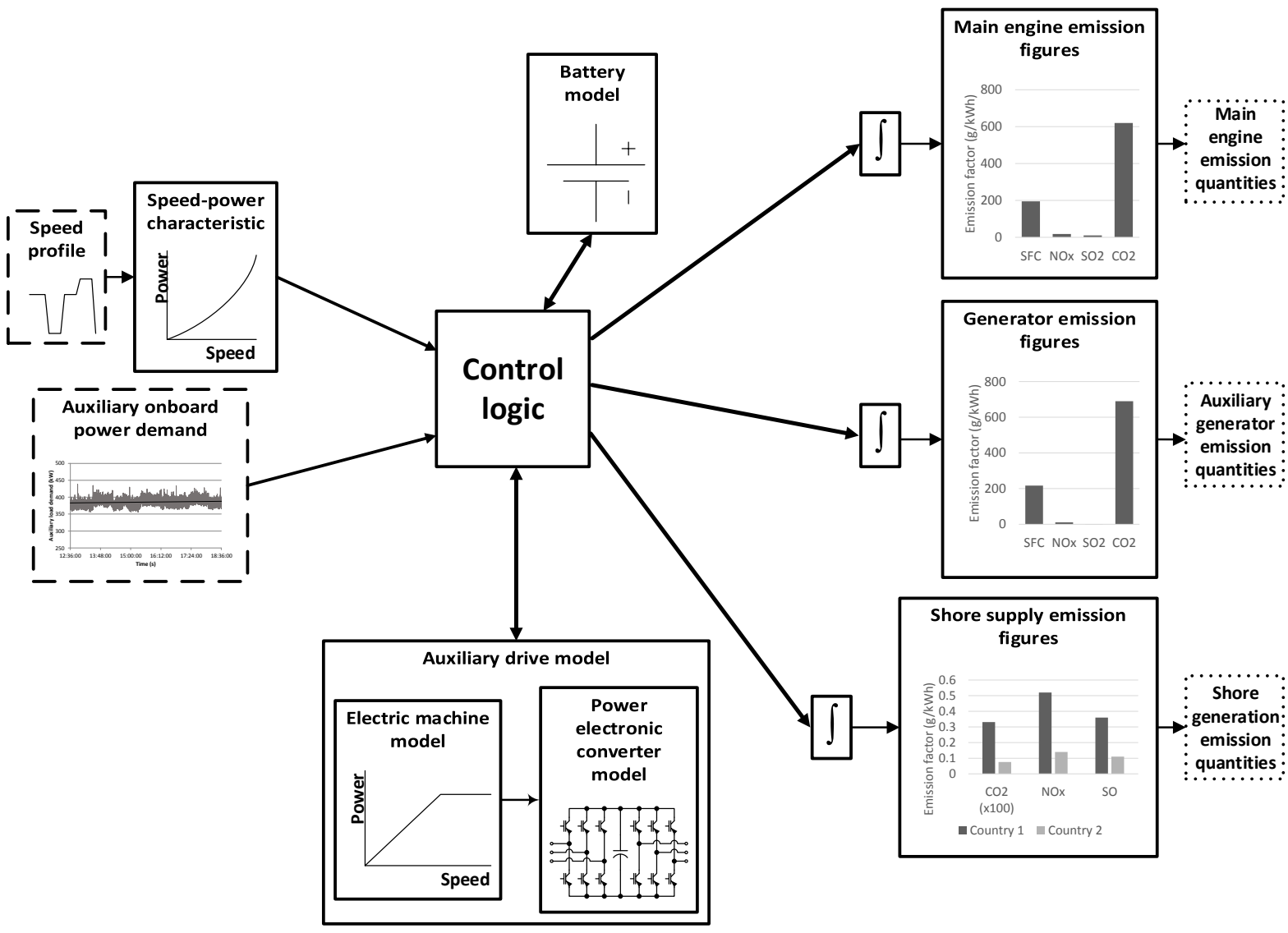

Figure 6. System model.

The power control logic is a rule-based system which assigns power to the individual sources following predetermined rules. Power is assigned to the three sources, main engine, auxiliary generators or shore supply and integrated over time in order to determine the energy from each source. The auxiliary drive and battery models calculate the power in and out of the component, such that this is then added to or subtracted from each source as necessary, ensuring that power is balanced between sources and demands at all instants.

The rule-based logic can be summarised as follows, and the resultant conditions shown in Figure 7:

- The auxiliary drive is selected to come online when the propulsion demand drops below the drive's rated power.

- Power is then provided from the batteries if charge is available. 
- Otherwise the auxiliary generator sets provide the propulsion power.

- When berthed, power is provided from the shore supply (if available)

$\circ$ Otherwise battery power is used if sufficient charge is available.

$\circ$ Alternatively the auxiliary generators are used.

- When at sea, the auxiliary drive is used as a shaft generator (if available).

$\circ$ Otherwise the auxiliary diesel generators are used.

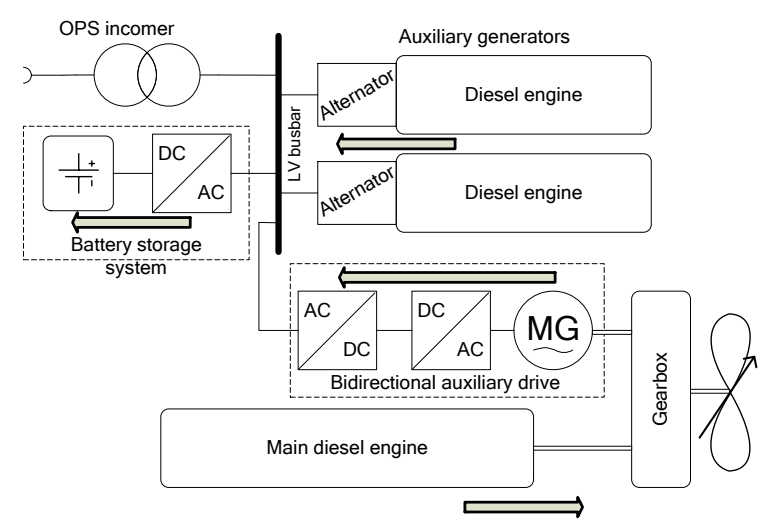

(a)

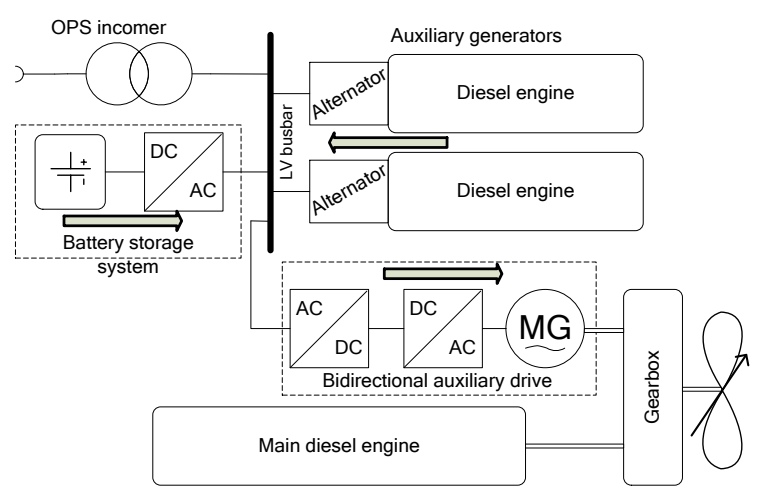

(b)

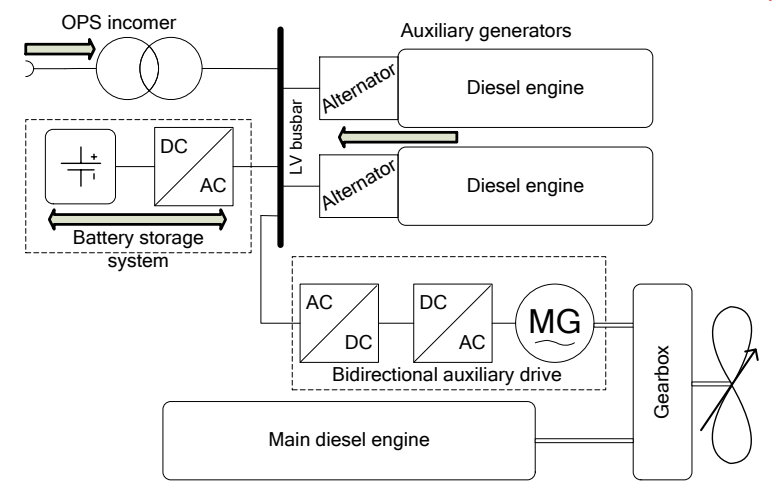

(c)

Figure 7 Power flows during the various operational modes as defined by the control logic; (a) At sea, (b) Slow speed sailing and (c) At berth.

Emission factors are used to convert the energy demanded from each source to equivalent airborne emissions and fuel consumption. These emission factors are available for different engine loadings and conditions, such that the effect of off-design loading can be investigated (Cooper, 2002), and are given in Table VI and Table VII. Similar figures have been derived for emissions generated onshore, based on the generating mix available in Table IV. This accounts for the emissions produced per unit of energy consumed, including the transmission losses for the location.

Table VI Emission factors for main engine running on HFO ("Bunkerworld," 2016; Cooper, 2002).

\begin{tabular}{llllll} 
Condition & $\mathrm{SFC}(\mathrm{g} / \mathrm{kWh})$ & $\begin{array}{l}\mathrm{CO}_{2} \\
(\mathrm{G} / \mathrm{KWH})\end{array}$ & $\begin{array}{l}\mathrm{NO} \\
(\mathrm{G} / \mathrm{KWH})\end{array}$ & $\begin{array}{l}\mathrm{SO}_{2} \\
(\mathrm{G} / \mathrm{KWH})\end{array}$ & $\begin{array}{l}\text { COST } \\
\text { (USD/MT) }\end{array}$ \\
\hline At sea & 213 & 677 & 14.0 & 11.5 & 147 \\
\hline Manoeuvring & 234 & 745 & 11.2 & 12.7 & 147 \\
\hline
\end{tabular}

Table VII Emission factors for auxiliary generator ("Bunkerworld," 2016; Cooper, 2002).

\begin{tabular}{llll}
$\mathrm{CO}_{2}(\mathrm{G} / \mathrm{KWH})$ & $\mathrm{NO} \times(\mathrm{G} / \mathrm{KWH})$ & $\mathrm{SO}_{2}(\mathrm{G} / \mathrm{KWH})$ & Cost (USD/mt) \\
\hline 690 & 10.9 & 0.275 & 307.9 \\
\hline
\end{tabular}


The baseline case is taken as the current existing setup, with no storage, cold ironing or auxiliary propulsion system. Propulsion is purely mechanical by means of a diesel main engine, while the auxiliary load is continuously supplied by auxiliary diesel generators even while at berth. While at sea, the necessary auxiliary power is provided via a shaft generator. The consumption and emission figures of this baseline case are summarised in Table VIII. The in-harbour period is defined as commencing when the vessel speed drops is below $10 \mathrm{kn}$, including when berthed.

Table VIII Baseline case (current setup).

\begin{tabular}{|c|c|c|c|c|c|}
\hline Source & Fuel cons. (t) & $\mathrm{CO}_{2}(T)$ & $N O_{x}(T)$ & $\mathrm{SO}_{2}(T)$ & $\begin{array}{l}\text { FUEL COST } \\
\text { (USD) }\end{array}$ \\
\hline & complete & complete & complete & complete & complete \\
\hline & $\begin{array}{l}\text { voyage/ } \\
\text { in-harbour }\end{array}$ & $\begin{array}{l}\text { voyage/ } \\
\text { in-harbour }\end{array}$ & $\begin{array}{l}\text { voyage/ } \\
\text { in-harbour }\end{array}$ & $\begin{array}{l}\text { voyage/ } \\
\text { in-harbour }\end{array}$ & $\begin{array}{l}\text { voyage/ } \\
\text { in-harbour }\end{array}$ \\
\hline & & & & & $12,309.9 /$ \\
\hline Main engine & $82.54 / 0.58$ & $262.4 / 1.86$ & $5.42 / 0.03$ & $4.46 / 0.03$ & 87.1 \\
\hline Auxiliary & & & & $1.64 \times 10^{-3} /$ & 383.6/ \\
\hline generator & $1.25 / 1.23$ & $3.99 / 3.95$ & $0.06 / 0.06$ & $1.62 \times 10^{-3}$ & 379.6 \\
\hline & & & & & $12,693.5 /$ \\
\hline Totals & $83.79 / 1.82$ & $266.39 / 5.81$ & $5.48 / 0.09$ & $4.46 / 0.04$ & 466.7 \\
\hline
\end{tabular}

Table IX and Table summarize fuel consumption and emissions results for the machinery configuration including auxiliary drive, onboard storage as well as shore supply. The fuel cost column also includes the cost of shoreside electricity based on the cost figures given in Table V. Two cases are considered, firstly when the batteries are only charged from the shore supply while berthed, and a second case where the batteries are also charged while at sea from the main engine. The case when charging only from shore (Table IX) implies the need for greater battery size, required in order to have sufficient capacity left over for the second leg of auxiliary propulsion, or alternately accepting a deeper discharge of the batteries, negatively affecting battery cycle life. When additionally charging while at sea from the main engine via the auxiliary drive (Table ), the costs involved are lower, though emission savings are also lower.

Table IX Results with auxiliary drive, batteries and cold ironing, charging from shore only. Fuel cost also includes cost of shoreside electricity.

\begin{tabular}{|c|c|c|c|c|c|c|}
\hline \multirow{4}{*}{\multicolumn{2}{|c|}{ Source }} & Fuel cons. (t) & $\mathrm{CO}_{2}(T)$ & $N O_{x}(T)$ & $\mathrm{SO}_{2}(T)$ & $\begin{array}{l}\text { FUEL COST } \\
\text { (USD) }\end{array}$ \\
\hline & & complete & complete & complete & complete & complete \\
\hline & & voyage/ & voyage/ & voyage/ & voyage/ & voyage/ \\
\hline & & in-harbour & in-harbour & in-harbour & in-harbour & in-harbour \\
\hline \multirow{2}{*}{\multicolumn{2}{|c|}{ Main engine }} & & & $5.39 / 1.97 \times 10^{-}$ & $4.43 / 2.29 \times 10^{-}$ & \\
\hline & & $82.00 / 0.04$ & $260.6 / 0.13$ & 3 & 3 & $12,229.4 / 6.12$ \\
\hline \multirow{2}{*}{\multicolumn{2}{|c|}{ Auxiliary generator }} & & & $1.16 \times 10^{-3} /$ & $2.92 \times 10^{-5} /$ & \\
\hline & & $0.02 / 0.01$ & $0.07 / 0.03$ & $4.94 \times 10^{-4}$ & $1.25 \times 10^{-5}$ & $6.83 / 2.92$ \\
\hline \multirow{2}{*}{ ূั } & Country 1 & & 1.37 & $2.15 \times 10^{-3}$ & $1.49 \times 10^{-3}$ & 340.26 \\
\hline & Country 2 & & 0.33 & $6.12 \times 10^{-4}$ & $4.81 \times 10^{-4}$ & 211.41 \\
\hline & & & & & $4.43 /$ & $12,787.90 /$ \\
\hline & Totals & $82.02 / 0.05$ & $262.37 / 1.86$ & $5.39 / 0.01$ & $4.28 \times 10^{-3}$ & 560.72 \\
\hline \multirow{2}{*}{\multicolumn{2}{|c|}{$\begin{array}{r}\text { Comparison with } \\
\text { baseline }\end{array}$}} & $-2.11 \% /$ & $-1.51 \% /$ & $-1.59 \% /$ & $-0.66 \% /$ & $0.74 \% /$ \\
\hline & & $-97.22 \%$ & $-67.90 \%$ & $-94.33 \%$ & $-87.17 \%$ & $20.14 \%$ \\
\hline
\end{tabular}


Table $X$ Results with the use of batteries and cold ironing with charging at sea. Fuel cost also includes cost of shoreside electricity.

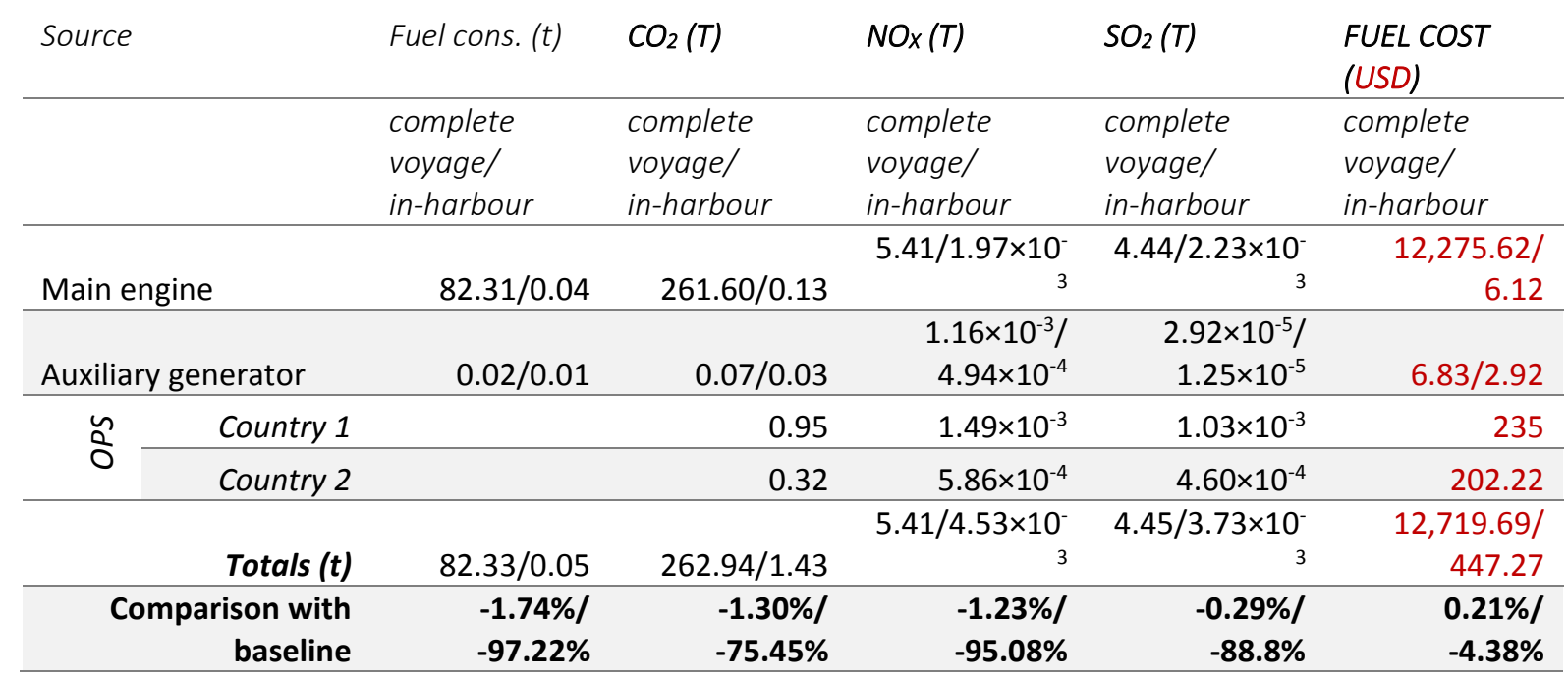

Figure 8 shows the averaged resultant power profiles obtained from the model, showing the power flows in/out of each component when considering the approach described in Table (charging both at shore and at sea). This shows the main engine providing propulsive power when at sea, together with brief increases in loads after port departure to recharge the batteries which have been discharged while slow sailing. The batteries are also recharged from shore, where the shore supply trace shows the additional contribution to supply the onboard auxiliary loads.

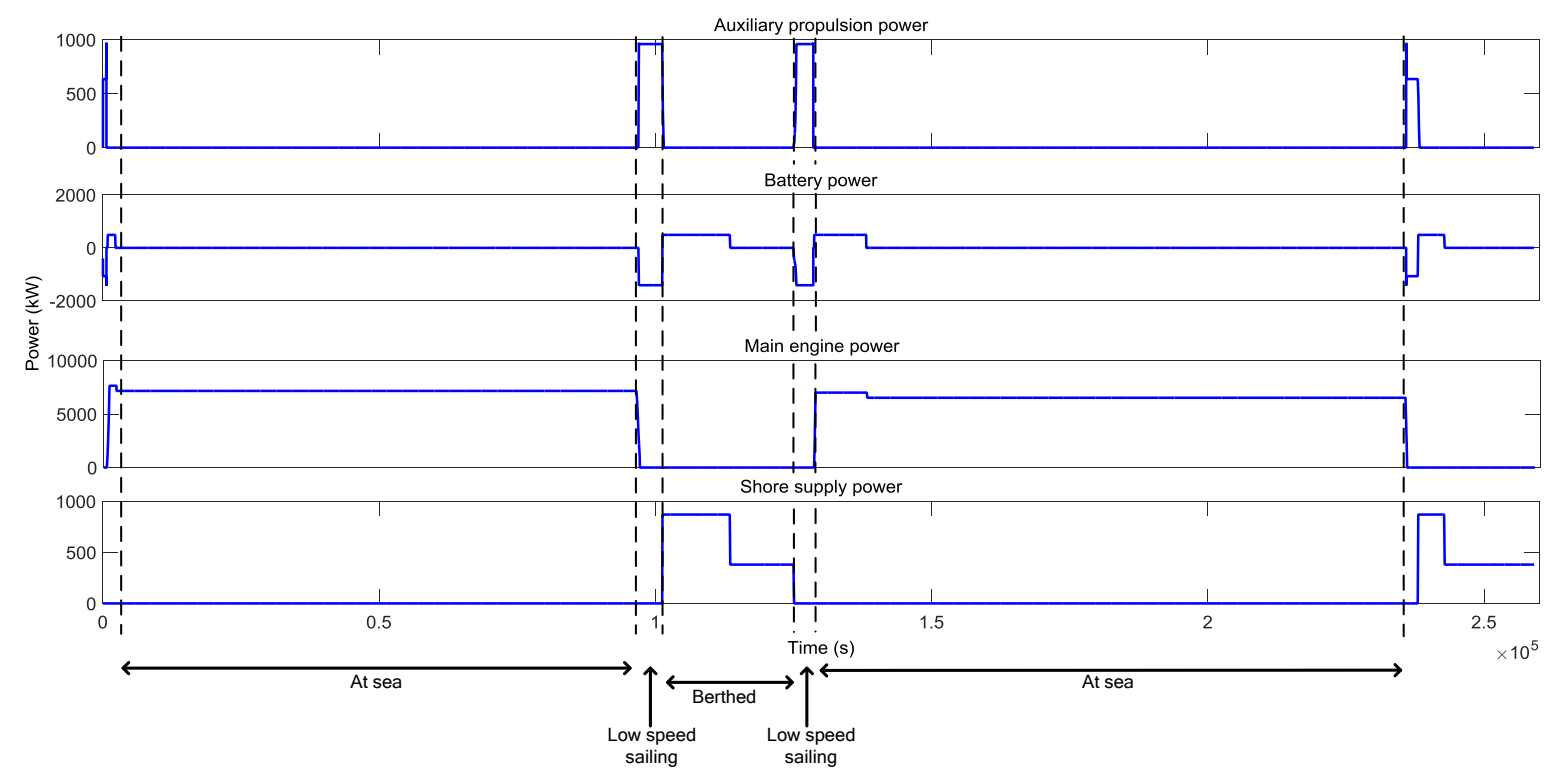

Figure 8 Power profiles of the various machinery components, illustrating operational modes.

Table XI gives the results for the case where onshore power supply is not available. Auxiliary drives and battery storage are used, with the batteries being charged from the main engine while at sea, and power while berthed provided from the auxiliary generator sets. This provides an increased use of HFO, only leading to small reductions in emissions (since main engine operation during 
manoeuvring is minimised) but also giving cost savings since reliance on expensive MGO and shoreside electricity is minimised.

Table XI Results with auxiliary drives and batteries, charging only at sea. No cold ironing.

\begin{tabular}{|c|c|c|c|c|c|}
\hline Source & Fuel cons. (t) & $\mathrm{CO}_{2}(\mathrm{~T})$ & $N O_{x}(T)$ & $\mathrm{SO}_{2}(T)$ & $\begin{array}{l}\text { FUEL COST } \\
\text { (USD) }\end{array}$ \\
\hline & complete & complete & complete & complete & complete \\
\hline & voyage/ & voyage/ & voyage/ & voyage/ & voyage/ \\
\hline & in-harbour & in-harbour & in-harbour & in-harbour & in-harbour \\
\hline & & & & $4.55 /$ & $12,303.96 /$ \\
\hline \multirow[t]{2}{*}{ Main engine } & $82.50 / 0.04$ & $262.20 / 0.13$ & $5.42 / 0.00$ & $2.23 \times 10^{-3}$ & 6.12 \\
\hline & & & & $1.12 \times 10^{-3} /$ & $257.48 /$ \\
\hline \multirow[t]{2}{*}{ Auxiliary generator } & $0.84 / 0.82$ & $2.68 / 2,64$ & $0.04 / 0.04$ & $1.1 \times 10^{-3}$ & 253.58 \\
\hline & & & & $4.55 /$ & $12,561.44 /$ \\
\hline Totals & $83.34 / 0.86$ & $264.88 / 2,77$ & $5.47 / 0.05$ & $3.33 \times 10^{-3}$ & 259.70 \\
\hline Comparison with & $-0.54 \% /$ & $-0.57 \% /$ & $-0.25 \% /$ & $1.96 \% /$ & $-1.04 \% /$ \\
\hline baseline & $-52.41 \%$ & $-52.36 \%$ & $-50.42 \%$ & $-90 \%$ & $-44.36 \%$ \\
\hline
\end{tabular}

Another case considered is the configuration without the addition of energy storage. This represents a cheaper solution, eliminating the need for batteries which significantly increase capital costs. It is also a more compact solution without requiring the significant footprint associated with the battery storage. Table XII summarizes these results, showing emissions and fuel consumption savings. However the net cost has increased, due to a higher demand on the auxiliary generators (running on expensive MGO) as well as shoreside electricity.

Table XII Results with use of auxiliary drive and use of cold ironing when berthed. Fuel cost also includes cost of shoreside electricity.

\begin{tabular}{|c|c|c|c|c|c|}
\hline Source & Fuel cons. (t) & $\mathrm{CO}_{2}(T)$ & $N O_{x}(T)$ & $\mathrm{SO}_{2}(T)$ & $\begin{array}{l}\text { FUEL COST } \\
\text { (USD) }\end{array}$ \\
\hline & complete & complete & complete & complete & complete \\
\hline & voyage/ & voyage/ & voyage/ & voyage/ & voyage/ \\
\hline & in-harbour & in-harbour & in-harbour & in-harbour & in-harbour \\
\hline & $82.00 / 0.04$ & $260.60 / 0.13$ & $5.39 / 0.00$ & $4.43 /$ & $12,229.33 /$ \\
\hline Main engine & & & & $2.23 \times 10^{-3}$ & 6.12 \\
\hline & $0.74 / 0.72$ & $2.36 / 2.32$ & $0.04 / 0.04$ & $1.05 \times 10^{-3} /$ & 226.84/ \\
\hline Auxiliary generator & & & & $1.01 \times 10^{-3}$ & 222.91 \\
\hline \multirow{2}{*}{ ธิ } & & 0.73 & $1.15 \times 10^{-3}$ & $7.96 \times 10^{-4}$ & 181.47 \\
\hline & & 0.19 & $3.52 \times 10^{-4}$ & $2.77 \times 10^{-4}$ & 121.49 \\
\hline \multirow[b]{2}{*}{ Totals (t) } & $82.74 / 0.77$ & $263.69 / 3.37$ & $5.43 / 0.04$ & $4.43 /$ & $12,759.21 /$ \\
\hline & & & & $4.31 \times 10^{-3}$ & 532.01 \\
\hline \multirow{2}{*}{$\begin{array}{r}\text { Comparison with } \\
\text { baseline }\end{array}$} & $-1.25 \% /$ & $-1.01 \% /$ & $-0.89 \% /$ & $-0.66 \% /$ & $0.52 \% /$ \\
\hline & $-57.89 \%$ & $-41.96 \%$ & $-52.65 \%$ & $-87.05 \%$ & $13.99 \%$ \\
\hline
\end{tabular}

The sensitivity to prices is demonstrated by considering the fuel cost five months previous to the prices of Table VI and Table VII, with the cost of HFO and MGO reported as USD237.61/mt and USD437.81/mt respectively. Results reflecting these updated prices are reported in Table XIII for the case when shore supply only is used to charge the onboard batteries and Table XIV for the case with no shore supply and using the main engine to charge the onboard batteries. Compared to the new 
baseline, cost savings are now seen even in the case with most use of shore supply, due to the higher cost of onboard fuels.

Table XIII Results for minimised main engine operation, charging only from shore with modified fuel cost. Fuel cost also includes cost of shoreside electricity.

\begin{tabular}{|c|c|c|c|c|c|c|}
\hline \multirow{3}{*}{\multicolumn{2}{|c|}{ Source }} & Fuel cons. (t) & $\mathrm{CO}_{2}(T)$ & $N O_{x}(T)$ & $\mathrm{SO}_{2}(T)$ & $\begin{array}{l}\text { FUEL COST } \\
\text { (USD) }\end{array}$ \\
\hline & & complete & complete & complete & complete & complete \\
\hline & & $\begin{array}{l}\text { voyage/ } \\
\text { in-harbour }\end{array}$ & $\begin{array}{l}\text { voyage/ } \\
\text { in-harbour }\end{array}$ & $\begin{array}{l}\text { voyage/ } \\
\text { in-harbour }\end{array}$ & $\begin{array}{l}\text { voyage/ } \\
\text { in-harbour }\end{array}$ & $\begin{array}{l}\text { voyage/ } \\
\text { in-harbour }\end{array}$ \\
\hline \multirow{2}{*}{\multicolumn{2}{|c|}{ Main engine }} & & & $5.39 / 1.97 \times 10^{-}$ & $4.43 / 2.29 \times 10^{-}$ & $19,484.11 /$ \\
\hline & & $82.00 / 0.04$ & $260.6 / 0.13$ & 3 & 3 & 9.76 \\
\hline \multirow{2}{*}{\multicolumn{2}{|c|}{ Auxiliary generator }} & & & $0.00 / 4,94 \times 10^{-}$ & $2.92 \times 10^{-5} /$ & \\
\hline & & $0.02 / 0.01$ & $0.07 / 0.03$ & 4 & $1.25 \times 10^{-5}$ & $9.72 / 4.16$ \\
\hline \multirow{4}{*}{ ธั } & Country 1 & & 1.37 & $1.49 \times 10^{-3}$ & $1.49 \times 10^{-3}$ & 340.27 \\
\hline & Country 2 & & 0.33 & $4.81 \times 10^{-4}$ & $4.81 \times 10^{-4}$ & 211.41 \\
\hline & & & & & $4.43 /$ & $20,045.51 /$ \\
\hline & Totals & $82.02 / 0.05$ & $262.37 / 1.86$ & $5.39 / 0.01$ & $4.28 \times 10^{-3}$ & 565.59 \\
\hline \multirow{2}{*}{\multicolumn{2}{|c|}{$\begin{array}{r}\text { Comparison with } \\
\text { baseline }\end{array}$}} & $-2.11 \% /$ & $-1.51 \% /$ & $-1.59 \% /$ & $-0.66 \% /$ & $-0.56 \% /$ \\
\hline & & $-97.22 \%$ & $-67.90 \%$ & $-95.33 \%$ & $-87.17 \%$ & $-16.65 \%$ \\
\hline
\end{tabular}

Table XIV Results for maximum main engine usage, with no shore supply using modified fuel cost.

\begin{tabular}{|c|c|c|c|c|c|}
\hline Source & Fuel cons. (t) & $\mathrm{CO}_{2}(T)$ & $N O_{x}(T)$ & $\mathrm{SO}_{2}(T)$ & $\begin{array}{l}\text { FUEL COST } \\
\text { (USD) }\end{array}$ \\
\hline & complete & complete & complete & complete & complete \\
\hline & voyage/ & voyage/ & voyage/ & voyage/ & voyage/ \\
\hline & in-harbour & in-harbour & in-harbour & in-harbour & in-harbour \\
\hline \multirow[b]{2}{*}{ Main engine } & & & & $4.55 /$ & $19,602.92 /$ \\
\hline & $82.50 / 0.04$ & $262.20 / 0.13$ & $5.42 / 0.00$ & $2.23 \times 10^{-3}$ & 9.76 \\
\hline \multirow{3}{*}{ Auxiliary generator } & & & & $1.12 \times 10^{-3} /$ & $366.14 /$ \\
\hline & $0.84 / 0.82$ & $2.68 / 2.64$ & $0.04 / 0.04$ & $1.1 \times 10^{-3}$ & 360.58 \\
\hline & & & & $4.55 /$ & $19,969.05 /$ \\
\hline Totals & $83.34 / 0.86$ & $264.88 / 2,77$ & $5.47 / 0.05$ & $3.33 \times 10^{-3}$ & 370.33 \\
\hline Comparison with & $-0.54 \% /$ & $-0.57 \% /$ & $-0.25 \% /$ & $1.96 \% /$ & $-0.94 \% /$ \\
\hline baseline & $-52.41 \%$ & $-52.36 \%$ & $-50.42 \%$ & $-90 \%$ & $-45.43 \%$ \\
\hline
\end{tabular}

Results show that when considered over the complete profile of the journey, potential fuel and emission savings are around $2 \%$. Costs on the other hand are generally increased due to more expensive MGO as well as the cost of shoreside electricity. The cheapest option giving the greatest cost savings is obtained by increasing the use of the main engine running on HFO (low cost fuel), charging the batteries at sea via the auxiliary drive then using the batteries for slow sailing and to provide the auxiliary power when berthed. The elimination of the use of the main engine while slow sailing results in a reduction in fuel consumption of $0.54 \%$.

Conversely, the solutions giving the greatest fuel and $\mathrm{CO}_{2}$ reductions are based on reducing the use of the main engine as much as possible, charging only from shore and with minimal use of the auxiliary generators giving a $2.1 \%$ reduction in fuel consumption (combined HFO and MGO). However this entailed a $0.74 \%$ cost increase when compared to the current baseline case. 
Fuel cost is highly variable, depending on location, supplier agreements as well as unpredictable price trends. Shore emission figures are very subjective as well, dependent on locations whose generation mix will determine the net emissions from shore supply power.

The sensitivity to fuel costs is illustrated by a sensitivity analysis performed for fuel costs variations over one year. The results are summarised in Figure 9 which shows the percentage change in fuel cost, compared to the conventional machinery configuration (baseline case), calculated at five different times between August 2015 and August 2016. Interestingly, the solution which seems to be most insensitive to fuel price is the one which maximises main engine usage by charging the onboard batteries from the main engine only (final column in Figure 9). This is understandable since the comparison is made with the diesel-only baseline case.

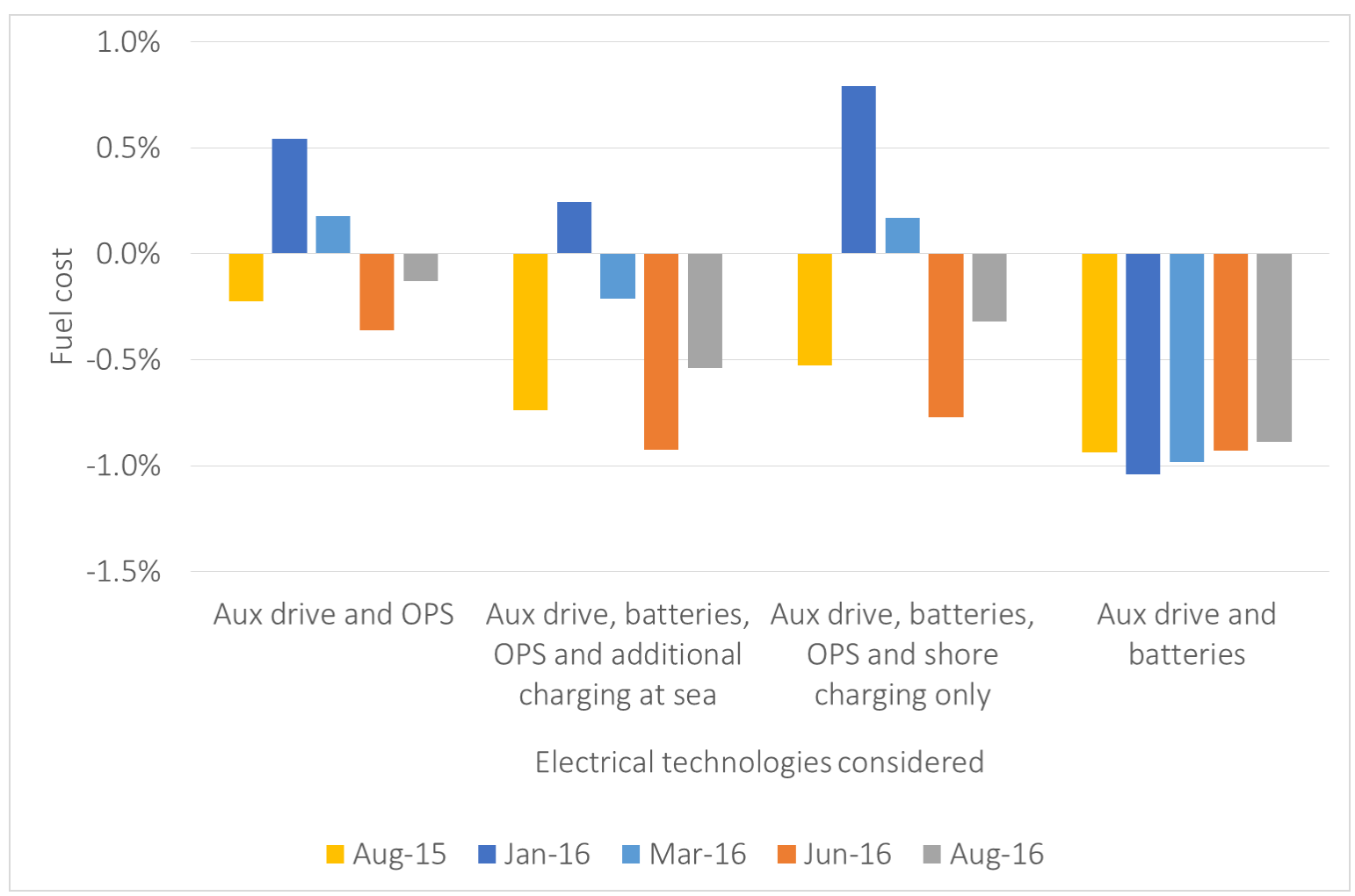

Figure 9 Comparison of percentage change in fuel costs for different electrical technology combinations over a period of one year.

The results are given over the complete voyage, and immediately highlight the low proportion of time spent manoeuvring or at berth, as summarised in Table II. This implies that savings during these periods will not heavily influence the total consumption and emission figures. However, it must be borne in mind that these operating conditions occur in-harbour or close to shore, thus emission reductions here will have a more direct impact on human health. Considering solely the in-harbour period (considered in this case as being when the ship sails below $10 \mathrm{kn}$ and also when at berth), significant emission reductions are seen when compared to the baseline case.

\section{Conclusions}

Electrification of shipboard systems offers opportunities for emission and fuel reductions by introducing operational flexibility in the onboard machinery system. Reducing emissions in harbour and during harbour approach gives health benefits disproportionally higher than the actual time spent in these conditions. In this work, a real ship's operational profile together with actual ship data were used to study the effects on fuel consumption and airborne emissions of three different 
electric technologies fitted to the vessel, namely auxiliary drives, onboard battery storage and onshore power supply.

A framework for modelling and assessing different onboard machinery systems was developed, which returns the steady state fuel consumption and emission figures based on the vessel's operational profile over a complete journey. Simulations were run for the various machinery configurations and compared to the existing setup. Fuel and emission savings as well as economic improvements have been demonstrated, as well as the sensitivity to changes in fuel prices.

The results of this work highlight the importance of consideration of the operational profile in order to examine the feasibility and savings possible with new machinery solutions. Strategies which reduce main engine usage were shown to give the highest fuel and emission savings, emphasising shore supply and battery use. Yet this must be balanced by the economic aspect, which is highly dependent on utility costs. A sensitivity analysis has shown how a configuration which maximizes the main engine operation through the use of batteries and an auxiliary drive gives the highest and most consistent fuel cost savings, while being relatively insensitive to fuel price variations.

With a relatively low proportion of time in-harbour, savings while slow sailing and at berth will not significantly affect the net voyage emissions. However the impact is more directly felt due to proximity to human habitation, and seen in context, emissions are drastically reduced. All three technologies (auxiliary drives, batteries and onshore power supply) give significant in-harbour emissions savings. However, selecting options that are economically feasible is the key to make these actually happen.

\section{Acknowledgements}

The authors wish to acknowledge funding received from the European Union Seventh Framework Programme FP7/2007-2013 (TEFLES project, grant agreement no. 266126).

\section{References}

Alahakoon, S., Leksell, M., 2015. Emerging energy storage solutions for transportation - a review, in: 2015 International Conference on Electrical Systems for Aircraft, Railway, Ship Propulsion and Road Vehicles (ESARS). Presented at the 2015 International Conference on Electrical Systems for Aircraft, Railway, Ship Propulsion and Road Vehicles (ESARS), pp. 1-6. doi:10.1109/ESARS.2015.7101490

Alexander, D., 2015. Hybrid Electric Drive for Naval Combatants. Proceedings of the IEEE 103, 2267-2275. doi:10.1109/JPROC.2015.2453395

Argyros, D., Smith, T., Raucci, C., Sabio, N., 2014. Global marine fuel trends 2030. Lloyd's Register and University College London.

Banks, C., Turan, O., Incecik, A., Theotokatos, G., Izkan, S., Shewell, C., Tian, X., 2013. Understanding ship operating profiles with an aim to improve energy efficient ship operations, in: Low Carbon Shipping Conference, London 2013. UCL, pp. 1-11.

Bunkerworld [WWW Document], 2016. URL http://www.bunkerworld.com/ (accessed 9.13.16).

Castles, G., Reed, G., Bendre, A., Pitsch, R., 2009. Economic benefits of hybrid drive propulsion for naval ships, in: Electric Ship Technologies Symposium, 2009. ESTS 2009. IEEE. pp. 515-520. doi:10.1109/ESTS.2009.4906560

Cooper, D., 2002. Representative emission factors for use in Quantification of emissions from ships associated with ship movements between ports in the European Community. IVL Swedish Environmental Research Institute Ltd., Göteborg. 
Finch, J.W., Giaouris, D., 2008. Controlled AC Electrical Drives. IEEE Transactions on Industrial Electronics 55, 481-491. doi:10.1109/TIE.2007.911209

Hall, W.J., 2010. Assessment of CO2 and priority pollutant reduction by installation of shoreside power. Resources, Conservation and Recycling 54, 462-467. doi:10.1016/j.resconrec.2009.10.002

Horiba, T., 2014. Lithium-Ion Battery Systems. Proceedings of the IEEE 102, 939-950. doi:10.1109/JPROC.2014.2319832

IEA, 2012. Key World Energy Statistics. International Energy Agency.

IEC/ISO/IEEE Utility Connections in Port-Part 1: High Voltage Shore Connection (HVSC) Systems-General requirements, 2012. IEC/ISO/IEEE 80005-1:2012 1-68. doi:10.1109/IEEESTD.2012.6243150

IMO, 2005. Annex VI, Prevention of Air Pollution from Ships. MARPOL 73/78, International Convention for the Prevention of Pollution from Ships.

Khersonsky, Y., Islam, M., Peterson, K., 2007. Challenges of Connecting Shipboard Marine Systems to Medium Voltage Shoreside Electrical Power. Industry Applications, IEEE Transactions on 43, 838-844. doi:10.1109/TIA.2007.895810

McArthur, D.P., Osland, L., 2013. Ships in a city harbour: An economic valuation of atmospheric emissions. Transportation Research Part D: Transport and Environment $21,47-52$.

Murphy, A.J., Weston, S.J., Young, R.J., 2012. Reducing Fuel Usage and CO2 Emissions from Tug Boat Fleets: Sea Trials and Theoretical Modelling. International Journal of Maritime Engineering 154, A31-A41.

Prousalidis, J., Hatzilau, I.K., Michalopoulos, P., Pavlou, I., Muthumuni, D., 2005. Studying ship electric energy systems with shaft generator, in: Electric Ship Technologies Symposium, 2005 IEEE. pp. 156-162. doi:10.1109/ESTS.2005.1524669

Sciberras, E.A., Zahawi, B., Atkinson, D.J., 2015a. Electrical characteristics of cold ironing energy supply for berthed ships. Transportation Research Part D: Transport and Environment 39, 31-43. doi:10.1016/j.trd.2015.05.007

Sciberras, E.A., Zahawi, B., Atkinson, D.J., Juandó, A., 2015b. Electric auxiliary propulsion for improved fuel efficiency and reduced emissions. Proceedings of the Institution of Mechanical Engineers, Part M: Journal of Engineering for the Maritime Environment 229, 36-44.

Sciberras, E.A., Zahawi, B., Atkinson, D.J., Juandó, A., Sarasquete, A., 2016. Cold ironing and onshore generation for airborne emission reductions in ports. Proceedings of the Institution of Mechanical Engineers, Part M: Journal of Engineering for the Maritime Environment 230, 67-82. doi:10.1177/1475090214532451

The European Parliament and the Council of the European Union, 2012. Directive 2012/33/EC. Official Journal of the European Union.

Vazquez, S., Lukic, S.M., Galvan, E., Franquelo, L.G., Carrasco, J.M., 2010. Energy Storage Systems for Transport and Grid Applications. IEEE Transactions on Industrial Electronics 57, 3881-3895. doi:10.1109/TIE.2010.2076414 